\title{
River Channel Forms in Relation to Bank Steepness: A Theoretical Investigation Using a Variational Analytical Method
}

\author{
Jinsheng Fan ${ }^{1,2}$, Heqing Huang ${ }^{1,2, *(\mathbb{C}, \text { Guoan } \mathrm{Yu}}{ }^{1} \mathbb{D}$ and Teng Su ${ }^{1}$ \\ 1 Key Lab. of Water Cycle and Related Land Surface Processes, Institute of Geographic Sciences and Natural \\ Resources Research, Chinese Academy of Sciences, Beijing 100101, China; fanjs.16b@igsnrr.ac.cn (J.F.); \\ yuga@igsnrr.ac.cn (G.Y.); sut.12s@igsnrr.ac.cn (T.S.) \\ 2 College of Resources and Enviroment, University of Chinese Academy of Sciences, Beijing 100049, China \\ * Correspondence: huanghq@igsnrr.ac.cn
}

Received: 28 March 2020; Accepted: 21 April 2020; Published: 28 April 2020

check for updates

\begin{abstract}
Riverbanks vary considerably in anti-scourability and consequently take various profiles. By using an isosceles trapezoid as the generalized form of river channel cross-sections and then incorporating the effects of bank angle into the variational analytical approach developed by Huang and Nanson (2000), this study presents a detailed theoretical investigation of the self-adjustment of alluvial channel forms. It is demonstrated that when alluvial channel flow achieves stable equilibrium, a significant decrease in riverbank steepness leads to a slight decrease in maximum sediment (bedload) discharge, and yet results in a significant increase in optimal channel width and a considerable decrease in optimal channel depth. The hydraulic geometry relations, theoretically derived for bank steepness to vary across a wide range, show that among the multivariant controls, the roles of bed sediment size, channel roughness, flow discharge and sediment (bedload) discharge are independent of bank steepness. While the effects of bank steepness illustrated in the theoretically derived hydraulic geometry relations are highly consistent with the results of threshold theory and previous empirical studies, limitations on using bank angle to reflect the anti-scourability of natural riverbanks are also highlighted.
\end{abstract}

Keywords: alluvial rivers; riverbank anti-scourability; variational method; equilibrium; river channel forms

\section{Introduction}

Rivers are self-adjusting systems and able to reach a dynamic equilibrium state of neither erosion nor deposition through adjusting their channel geometry and gradient $[1,2]$. The dynamic equilibrium state of rivers is a very important concept in fluvial geomorphology and river engineering for it embodies the physical mechanism governing the complex interactions among river flow, sediment transport and channel forms. Although rivers in many circumstances can deviate from the state of dynamic equilibrium, the state determines the adjusting direction of river channel forms as it acts as an attractor in river systems [3-5]. In recent decades, many rivers encounter intensive human disturbances, such as riverbank reinforcement, dam construction, floodplain occupation for urbanization and agricultural development, logging practices and many more, and so it is urgent to know to what an extent these rivers deviate from dynamic equilibrium, or if they are capable of regaining dynamic equilibrium. Hence, determination of the state of dynamic equilibrium in river channel flow not only helps to deepen our understanding on how rivers function properly, but can also offer valuable guides to the practices of preservation and restoration of river systems [6].

For a long time, however, studies of river channel forms in equilibrium have been dominated with empirical approaches, mainly in the forms of providing qualitative descriptions [7-9] or developing 
statistical hydraulic geometry relations [10-21]. Although the empirical studies have limitations, typically on uncovering the physical mechanism underlying the self-adjustment of river systems, they provide a reference for verifying the results of theoretical analyses.

In the process of developing equilibrium theory for understanding the behaviors of river systems, there is a scientific problem that needs to be solved: three basic equations governing river channel flow (flow continuity, friction and sediment transport equations) in contrast to four unknown variables (channel width, depth, slope and flow velocity). To solve the mathematically nonclosure problem, many hypotheses have been put forward largely in the way of developing an additional flow equation, typically the so-called stability theories and extreme hypotheses. In the early stages, stability theories were concentrated on the development of "threshold theory", which assumes that sediment on the entire channel boundary is in the critical state for incipient motion in order to make channel flow maintain stability [2,7]. Later on, stability theories were focused on the conditions that make flow achieve stability in alluvial channels with equilibrium banks and a mobile bed [22-25]. Although stability theories provide a reasonable physical explanation for river channel-form adjustment, the analytical methods they provided in terms of Newtonian formulations are very difficult to use, and the results they produced are not very satisfactory in many cases [26].

Similar to stability theories, the approach of extremal hypotheses tries to adopt an extremal condition as an additional flow equation, such as minimum energy gradient [27-34], maximum sediment transport capacity [35], minimum energy loss rate [36-45], etc. Although this approach is relatively easy to apply, its applications have led to considerable controversies. The main reasons of the opponents against using extremal hypotheses are: (1) river channel width calculated by using extreme hypotheses is always smaller than the observed; and (2) all extreme hypotheses are not based on sufficiently convincing physical mechanisms [46,47]. On the contrary, the supporters argue that extremal hypotheses are based on generally applicable physical principles, such as the principles of minimum work, maximum entropy, etc. [48-50]. In addition, Eaton and Millar (2004) deem that the opponents applied the extremal approach in an incomplete form and did not consider the impacts of riverbank anti-scourability on river channel forms [49,51]. On the basis of a series of studies, Eaton and Millar (2017) developed a so-called UBC model by incorporating the repose angle of bank sediment into their extremal hypothesis-based framework. Since the incorporation makes the UBC model able to reflect the effects of riverbank anti-scourability, the model provides acceptable computations of alluvial channel forms in many situations [26].

Different from stability theories and extremal hypothesis approach, Huang and Nanson (2000) developed a variational analytical approach, which elucidates the physical mechanism governing the self-adjustment of river channel-forms in an easily understandable way. By using channel width/depth ratio as a variational variable to reflect the shape of river channel cross-sections, it can be found that the number of independent variables in the basic relationships governing alluvial channel flow, i.e., relationships of flow continuity, resistance and sediment (bedload) transport, can be reduced and the response of sediment discharge to the variation of channel width/depth ratio, illustrated simply with a curve-drawing method. As a result, stable equilibrium state is identifiable where sediment transport discharge reaches a maximum or energy gradient achieves a minimum. Importantly, the conditions of maximum sediment transport discharge and minimum energy gradient have been demonstrated to be the different realization forms of the general physical principle of least action in river systems [3-6,52-55].

Although the variational analytical approach developed by Huang and Nanson (2000) is physically sound and able to provide acceptable calculations of river channel forms in many circumstances [53-56], it has not taken into account the impacts of riverbank anti-scourability. So far, the variational analytical approach has been applied only to river channels that take a rectangular cross-section, with the angle of $90^{\circ}$ between riverbanks and riverbed. It is well known that the anti-scourability of riverbanks is related closely to the angle of riverbanks or bank steepness in many situations [51,57-60], and so it is necessary to examine the applicability of the variational analytical approach to the determination of the 
impacts of bank steepness on alluvial channel forms. Aiming at this objective, this study deploys an isosceles trapezoid as the generalized cross-sectional form of alluvial channels, and then incorporates the effects of bank angle into the variational analytical approach developed by Huang and Nanson (2000) [53]. Consequently, conditions that make alluvial channel flow achieve stable equilibrium can be defined and theoretical hydraulic geometry relations derived. Finally, the effects of bank angle on alluvial channel forms are elucidated in detail, and the applicability of the theoretically derived hydraulic geometry models is evaluated in comparison with the results from previous studies.

\section{Basic Flow Relations in an Open Channel with Bedload Transport}

Riverbanks are normally composed of various materials, and thus they differ significantly in anti-scourability, consequently taking considerably different bank profiles. To study the effect of riverbank anti-scourability on channel forms, many generalized models have been adopted to reflect the variation of channel bank profile $[12,13,26,49]$. In terms of previous studies by Eaton and Millar [26,49,51], this study adopts an isosceles trapezoid as the generalized cross-sectional form of river channels at bankfull level as shown in Figure 1, and so the steepness of channel banks, or the angle of channel banks $\theta$, can be regarded as the main factor reflecting the anti-scourability of the banks.

For flow to maintain continuity in an alluvial channel, the following one-dimensional relationship is applied:

$$
Q=V A
$$

where $Q, V$ and $A$ are the flow discharge, average flow velocity and cross-sectional area of the channel at bankfull level, respectively.

For uniform and turbulent flow in an open channel, the following Manning formula has been widely applied to determine flow resistance:

$$
V=\frac{1}{n} R^{2 / 3} S^{1 / 2}
$$

where $n, R$ and $S$ are the roughness coefficient, hydraulic radius and channel slope of the study channel, respectively.

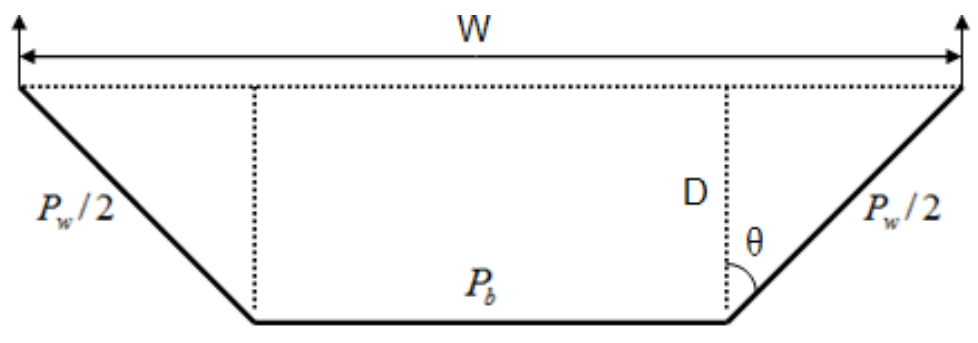

Figure 1. The schematic diagram of the generalized cross-section of river channels.

The shear force of flow has been widely regarded as the main driving factor for bedload movement [61-65] and the resultant numerous bedload transport formulas take the generalized form of:

$$
q_{b}=c_{b} \tau_{0}^{i}\left(\tau_{0}-\tau_{c}\right)^{j}
$$

where $q_{b}$ is the rate of bedload transport on the unit width of channel bed, $c_{b}$ is a coefficient, $\tau_{b}$ is the average shear stress of flow acting on the entire cross-section of the channel $\left(\tau_{0}=\gamma\right.$ RS), $\tau_{c}$ is the critical shear stress for the incipient motion of bed sediment, and $i$ and $j$ are exponents.

In many circumstances, the following simplified form of Equation (3) has been demonstrated capable of yielding acceptable results:

$$
q_{b}^{*}=c_{b}\left(\tau_{0}^{*}-\tau_{c}^{*}\right)^{j}
$$


where $q_{b}^{*}, \tau_{0}^{*}, \tau_{c}^{*}$ are, respectively, the dimensionless bedload transport rate on unit width of channel bed, the dimensionless average flow shear stress, and the dimensionless critical flow shear stress, which separately take the following specific expressions:

$$
q_{b}^{*}=\frac{q_{b}}{\sqrt{\left(\gamma_{s} / \gamma-1\right) g d^{3}}}=\frac{Q_{s} / P_{b}}{\sqrt{\left(\gamma_{s} / \gamma-1\right) g d^{3}}} ; \tau_{0}^{*}=\frac{\tau_{0}}{\left(\gamma_{s}-\gamma\right) d}=\frac{\gamma R S}{\left(\gamma_{s}-\gamma\right) d} ; \tau_{c}^{*}=\frac{\tau_{c}}{\left(\gamma_{s}-\gamma\right) d}
$$

In Equation (5), $P_{b}$ is the wetted perimeter of channel bed (equivalent to the width of channel bed as shown in Figure 1), on which bedload transport takes place, $Q_{s}$ is the sediment discharge in the form ofthe rate of bedload transport over the whole channel bed $P_{b}, \gamma_{s}$ and $\gamma$ are the specific weight of sediment particles and water, respectively, $\rho_{s}$ and $\rho$ are the density of sediment particles and water, respectively $\left(2650 \mathrm{~kg} / \mathrm{m}^{3}\right.$ and $1000 \mathrm{~kg} / \mathrm{m}^{3}$, respectively), $g$ is the gravity acceleration $\left(9.8 \mathrm{~m} / \mathrm{s}^{2}\right)$, and so $\gamma_{s}=\rho_{s} g$ and $\gamma=\rho g$.

In Equation (4), $c_{b}, \tau_{c}^{*}$ and $j$ have been given considerably different corresponding values in various studies $[61,64,65]$, among which, Huang (2010) argued based on a solid theoretical analysis of the interactions among channel geometry, bedload transport and flow resistance, that $j$ should take a value of 5/3. Consequently, fitting Equation (4) with a wide range of laboratory observations yields the most suitable values of $c_{b}$ and $\tau_{c}^{*}$ to be 6 and 0.047 , respectively, leading Equation (4) to take a specific form of:

$$
q_{b}^{*}=6\left(\tau_{0}^{*}-0.047\right)^{5 / 3}
$$

\section{Variational Analysis of the Effect of Channel-Form Adjustment on Bedload Transport}

According to the variational analytical method developed by Huang and Nanson [53], the crosssectional shape factor of river channels, i.e., width-depth ratio $\zeta$, needs to be treated as a variational variable, which for the trapezoid-form channel shown in Figure 1 is defined as:

$$
\zeta=\frac{W}{D}
$$

where $W$ and $D$ are the width and depth of the channel, respectively.

For the channel form shown in Figure 1, the following geometric relationships maintain:

$$
P_{b}=(\zeta-2 \tan \theta) D, R=(\zeta-\tan \theta)(\zeta+2 \sec \theta-2 \tan \theta)^{-1} D
$$

By incorporating the channel geometrical relationships in Equations (7) and (8) into the relationships of flow continuity and resistance presented in Equations (1) and (2), channel width $W$, depth $D$ and flow shear stress $\tau_{0}$ can be written as the functions of channel roughness coefficient $n$, flow discharge $Q$, channel slope $S$ and width-depth ratio $\zeta$ in the forms of:

$$
\begin{aligned}
W & =(n Q)^{3 / 8} S^{-3 / 16} \zeta(\zeta+2 \sec \theta-2 \tan \theta)^{1 / 4}(\zeta-\tan \theta)^{-5 / 8} \\
D & =(n Q)^{3 / 8} S^{-3 / 16}(\zeta+2 \sec \theta-2 \tan \theta)^{1 / 4}(\zeta-\tan \theta)^{-5 / 8} \\
\tau_{0} & =\gamma(n Q)^{3 / 8} S^{13 / 16}(\zeta+2 \sec \theta-2 \tan \theta)^{-3 / 4}(\zeta-\tan \theta)^{3 / 8}
\end{aligned}
$$

Consequently, by combining the bedload transport relationships presented in Equations (5) and (6) with Equation (9) and the relationship of $Q_{s}=q_{b} P_{b}$, bedload discharge $Q_{s}$ can be written as the function of width/depth ratio $\zeta$ and angle of riverbank slope $\theta$ in the form of:

$$
Q_{s}=\frac{K_{0}(\zeta+2 \sec \theta-2 \tan \theta)^{1 / 4}}{(\zeta-\tan \theta)^{5 / 8}(\zeta-2 \tan \theta)^{-1}}\left[K_{1} \frac{(\zeta+2 \sec \theta-2 \tan \theta)^{1 / 4}(\zeta-\tan \theta)^{3 / 8}}{(\zeta+2 \sec \theta-2 \tan \theta)}-0.047\right]^{5 / 3}
$$


where coefficients $K_{0}$ and $K_{1}$ take the following separate expressions:

$$
\begin{aligned}
& K_{0}=24.1275 d^{3 / 2}(n Q)^{3 / 8} S^{-3 / 16} \\
& K_{1}=\frac{\gamma(n)^{3 / 8}{ }^{13 / 16}}{\left(\gamma_{s}-\gamma\right) d}
\end{aligned}
$$

Assuming that flow discharge at bankfull $Q$ takes a value of $1600 \mathrm{~m}^{3} / \mathrm{s}$, channel slope or energy gradient $S$ is 2/10,000, sediment size $d$ is $0.3 \mathrm{~mm}$, and $n$ is 0.03 , the variations of $Q_{s}$ with a change in width-depth ratio $\zeta$ from 10 to 1000 are computed according to Equations (10) and (11) for bank slope $\theta$ to take each of the specific values of $0^{\circ}, 30^{\circ}, 45^{\circ}$ and $60^{\circ}$. Figure 2 and Table 1 present the computed results. It can be seen from Figure 2 that for each of the specific values of $\theta$, an increase in channel width-depth ratio $\zeta$ from 10 to 1000 makes $Q_{s}$ increase gradually at the early stage, then reach a maximum and afterwards decline gradually. Importantly, it is seen clearly that in the situation of $Q_{s}<Q_{s m a x m}$, a given $Q_{s} Q_{s}$ can be satisfied with two values of channel width-depth ratio $\zeta$ and only when $Q_{s}$ equals the maximum, or $Q_{s}=Q_{\text {smaxm }}$, does channel width-depth ratio $\zeta$ take a unique value of $\zeta_{m}$.

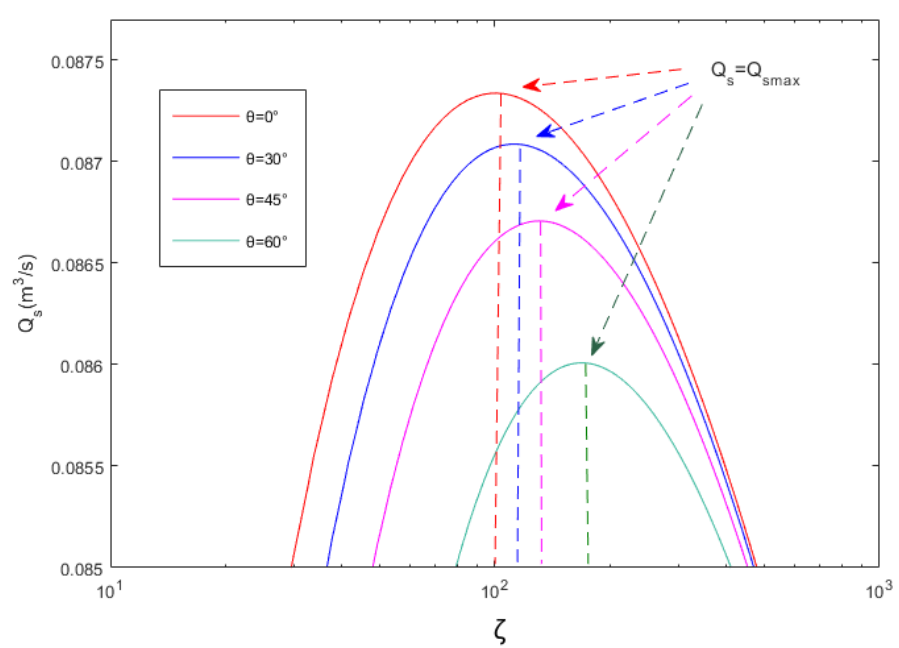

Figure 2. Relationships of bedload transport rate $Q_{s}$ against channel width/depth ratio $\zeta$ under different values of bank angle $\theta$.

As investigated in detail by Huang et al. (2004) and Nanson and Huang (2008, 2017, 2018), the physical mechanism underlying the results presented in Figure 2 is that in the situation of $Q_{s}=Q_{s m a x m}$, flow has no excessive power or energy to expend, and so can take only a unique channel which is neither very narrower and deeper nor very wider and shallower [3-6]. In contrast, flow has excessive power or energy to expend in the situation of $Q_{s}<Q_{s m a x m}$ and so can take either a much narrower and deeper channel or a much wider and shallower one, because the channels of the two shapes can yield much larger boundary resistance. Hence, in theory, the situation of $Q_{s}=Q_{s m a x m}$ reflects the most stable equilibrium state of river-channel flow and is the objective for flow to adjust channel geometry in the situation of $Q_{s}<Q_{s m a x m}$. That is to say, when a river channel possesses a fully adjustable boundary, it can achieve the most stable equilibrium state after a self-adjusting process from the situation of $Q_{s}<Q_{s m a x m}$. Therefore, the state of $Q_{s}=Q_{s m a x m}$ reflects the equilibrium state of all fully adjustable river channels (e.g., Huang et al., 2004; Nanson and Huang, 2008, 2017, 2018) [3-6].

If a river channel possesses only a partially adjustable boundary, it is not possible to adjust the channel to the most stable equilibrium state of $Q_{s}=Q_{\text {smaxm }}$ when flow is in the situation of $Q_{s}<Q_{s m a x m}$. As a result, the given conditions of channel slope, sediment size and straight single-channel planform have to change to some degrees. In the situation of $Q_{s}>Q_{\text {smaxm }}$, there is no mathematical solution of channel width-depth ratio because flow is short of sufficient energy to transport sediment load. Thus, 
aggradation becomes necessary, making not only channel geometry but also the given conditions of channel slope, sediment size and straight single-channel planform change to some degrees. These changes are generally in very complex forms and have been addressed largely in empirical manners (e.g., Schumm, 1971) [9].

Furthermore, it can be noticed from Figure 2 and Table 1 that when bank angle $\theta$ takes values of $0^{\circ}$, to $30^{\circ}, 45^{\circ}$ and finally $60^{\circ}$, the maximum values of $Q_{s}$ or $Q_{s m a x x}$, become smaller and smaller, with the corresponding values of $0.08733,0.08708,0.08670$ and $0.08601 \mathrm{~m}^{3} / \mathrm{s}$, respectively, while the corresponding optimal values of the width-depth ratio, or $\zeta_{m}$, become larger and larger, with the corresponding values of $101,113,128.7$ and 168.5 , respectively. When $\theta=30^{\circ}$ is taken as a reference level, it can be found from Table 1 that with $\theta$ taking respective values of $0^{\circ}, 45^{\circ}$ and $60^{\circ}, \zeta_{m}$ varies in the wide range of from $-10.62 \%$ to $49.12 \%$, while $Q_{\text {smax }}$ varies in the narrow range of from $-1.23 \%$ to $0.29 \%$. This demonstrates clearly that bank slope $\theta$ exerts a much more significant influence on optimal width-depth ratio of river channels, or $\zeta_{m}$, than on the maximum sediment (bedload) transport discharge $Q_{\text {smax }}$.

Table 1. Values of maximum sediment transport rate $Q_{s m a x}$ and optimal channel width/depth ratio $\zeta_{m}$ under different values of bank angle $\theta$.

\begin{tabular}{ccccc}
\hline $\boldsymbol{\theta}$ & $\zeta_{m}$ & $\frac{\zeta_{m}-\zeta_{m 0}}{\zeta_{m 0}}(\%)$ & $Q_{\text {smax }}\left(\mathrm{m}^{3} / \mathbf{s}\right)$ & $\frac{Q_{\text {smax }}-Q_{\text {smax }}}{Q_{\text {smax } 0}}(\%)$ \\
\hline $0^{\circ}$ & 101 & -10.62 & 0.08733 & 0.29 \\
$30^{\circ}$ & 113 & 0 & 0.08708 & 0 \\
$45^{\circ}$ & 128.7 & 13.89 & 0.08670 & -0.44 \\
$60^{\circ}$ & 168.5 & 49.12 & 0.08601 & -1.23 \\
\hline
\end{tabular}

When $n, Q, S$, and $\theta$ are taken as given constants, the following differential equations can be derived from the relationships presented in Equation (9):

$$
\begin{aligned}
\frac{1}{D} \frac{d D}{d \zeta} & =-\frac{(-3 \zeta-10 \sec \theta+8 \tan \theta)}{8(\zeta-\tan \theta)(\zeta+2 \sec \theta-2 \tan \theta)} \\
\frac{1}{W} \frac{d W}{d \zeta} & =\frac{8(\zeta-\tan \theta)(\zeta+2 \sec \theta-2 \tan \theta)+\zeta(-3 \zeta-10 \sec \theta+8 \tan \theta)}{8(\zeta-\tan \theta)(\zeta+2 \sec \theta-2 \tan \theta)} \\
\frac{1}{\tau_{0}} \frac{d \tau_{0}}{d \zeta} & =\frac{F-E \tan \theta-8(\zeta-\tan \theta)^{2}(\zeta+2 \sec \theta-2 \tan \theta)}{8(\zeta-\tan \theta)(\zeta+2 \sec \theta-2 \tan \theta)^{2}}
\end{aligned}
$$

where coefficients $F$ and $E$ are determined separately by:

$$
\begin{aligned}
& E=(-3 \zeta-10 \sec \theta+8 \tan \theta)(\zeta+2 \sec \theta-2 \tan \theta) \\
& F=[8(\zeta-\tan \theta)(\zeta+2 \sec \theta-2 \tan \theta)+\zeta(-3 \zeta-10 \sec \theta+8 \tan \theta)](\zeta+2 \sec \theta-2 \tan \theta)
\end{aligned}
$$

Taking into account the relationship of $Q_{s}=q_{b} P_{b}=q_{b}(W-2 D \tan \theta)$ and the bedload transport relationship presented in Equation (3), the following differential relationship of $Q_{s}$ against $\zeta$ can be derived:

$$
\frac{1}{Q_{s}} \frac{d Q_{s}}{d \zeta}=\frac{1}{W-2 D \tan \theta} \frac{d(W-2 D \tan \theta)}{d \zeta}+\left(i+\frac{\tau_{0} j}{\tau_{0}-\tau_{c}}\right) \frac{1}{\tau_{0}} \frac{d \tau_{0}}{d \zeta}
$$

When bedload discharge $Q_{s}$ reaches a maximum, the following condition needs to be satisfied:

$$
\frac{d Q_{s}}{d \zeta}=0
$$

which, in combination with the relationships in Equations (12) and (14), yields the following condition:

$$
\frac{\tau_{0}}{\tau_{c}}=\frac{F^{1}-C^{1}+B^{1} i}{F^{1}-C^{1}+B^{1}(i+j)}
$$


where parameters $F^{1}, B, B^{1}, C$ and $C^{1}$ take the following respective expressions:

$$
\begin{aligned}
& F^{1}=F(\zeta-\tan \theta) \\
& B=F-E \tan \theta-8(\zeta-\tan \theta)^{2}(\zeta+2 \sec \theta-2 \tan \theta) \\
& B^{1}=B(\zeta-2 \tan \theta) \\
& C=2 E \tan \theta \\
& C^{1}=C(\zeta-\tan \theta)
\end{aligned}
$$

When Equation (6) is adopted to determine the rate of bedload transport, $i$ and $j$ take respective values of 0 and 5/3, and consequently Equation (16) becomes:

$$
\frac{\tau_{0}}{\tau_{c}}=\frac{F^{1}-C^{1}}{F^{1}-C^{1}+(5 / 3) B^{1}}
$$

which is equivalent to:

$$
\frac{\tau_{0}-\tau_{c}}{\tau_{c}}=\frac{-(5 / 3) B^{1}}{A^{1}-C^{1}+(5 / 3) B^{1}}
$$

It can be seen from Equation (19) that to satisfy the condition that bedload discharge $Q_{s}$ reaches a maximum as defined in Equation (15), there is a lower threshold in the shear stress when $\tau_{0}=\tau_{c}$. At the threshold, it can be found from Equation (19) that it requires $B^{1}=0$, which, according to the expression of $B^{1}$ in Equation (17), can be satisfied with the condition of either $B=0$ or $\zeta-2 \tan \theta=0$. Although $B$ has a very complex relationship with $\theta$ and $\zeta$ as shown in Equation (17), it can be found that the condition of $B=0$ can be satisfied when $\zeta=\tan \theta$ or $\zeta=2 \sec \theta$. As a whole, there are three conditions that can make $B^{1}=0$ in Equation (19). Nevertheless, only the condition of $\zeta=2 \sec \theta$ can be regarded as reasonable because when $\theta=0$, the isosceles trapezoid cross-section of the study channel becomes a rectangle as shown in Figure 1, which yields $\zeta_{m}=2$ as what has been demonstrated in previous studies (e.g., Huang and Chang, 2006) [52]. Hence, the reasonable condition at the lower threshold of $\tau_{0}=\tau_{c}$ is:

$$
\zeta_{m c}=2 \sec \theta
$$

When bank angle $\theta$ takes respective values of $0^{\circ}, 30^{\circ}, 45^{\circ}$ and $60^{\circ}$, it can be computed from Equation (20) that the optimal width-depth ratio at the threshold, or $\zeta_{m c}$, takes values of 2, 2.3094, 2.8284 and 4, respectively. Clearly, the optimal width-depth ratio of the study channel at the lower threshold increases significantly with an increase in bank angle $\theta$ or a decrease in bank steepness.

\section{Effects of Riverbank Steepness on Equilibrium Channel Geometry}

\subsection{Equilibrium Channel Relations at the Lower Threshold}

When river flow is at the critical state for the incipient motion of bed sediment, i.e., $\tau_{0}=\tau_{c}$, combining Equation (20) with Equation (9) yields the following threshold equilibrium channel relations:

$$
\begin{aligned}
& W_{m c}=a Q^{6 / 13 \approx 0.46} \\
& D_{m c}=b Q^{6 / 13 \approx 0.46} \\
& S_{m c}=c Q^{-6 / 13 \approx-0.46}
\end{aligned}
$$

where coefficients $a, b$ and $c$ are determined respectively by the relationships of:

$$
\begin{aligned}
& a=c^{-3 / 16} n^{3 / 8}\left(\zeta_{m c}+2 \sec \theta-2 \tan \theta\right)^{1 / 4}\left(\zeta_{m c}\right)\left(\zeta_{m c}-\tan \theta\right)^{-5 / 8} \\
& b=c^{-3 / 16} n^{3 / 8}\left(\zeta_{m c}+2 \sec \theta-2 \tan \theta\right)^{1 / 4}\left(\zeta_{m c}-\tan \theta\right)^{-5 / 8} \\
& c=\left[0.047 \frac{\left(\gamma_{s}-\gamma\right) d}{\gamma\left(n^{3 / 8}\right)}\left(\zeta_{m c}+2 \sec \theta-2 \tan \theta\right)^{3 / 4}\left(\zeta_{m c}-\tan \theta\right)^{-3 / 8}\right]^{16 / 13}
\end{aligned}
$$


Assuming $n=0.03, d=0.3 \mathrm{~mm}, \rho_{s}=2650 \mathrm{~kg} / \mathrm{m}^{3}$ and $\rho=1000 \mathrm{~kg} / \mathrm{m}^{3}$, the values of coefficients $a, b$ and $c$ in Equation (21) are then computed according to Equation (22) when bank angle $\theta$ takes respective values of $0^{\circ}, 30^{\circ}, 45^{\circ}$ and $60^{\circ}$. Table 2 presented the computed results and it can be seen that with $\theta$ taking different values, the coefficients in the relations change in complex forms. Specifically, coefficient $a$ increases significantly with an increase of $\theta$, while coefficients $b$ and $c$ vary in complex forms within very small ranges and maintain the relationship of $b \cdot c \approx 4.6 \cdot 10^{-5}$. This demonstrates clearly that when flow in a river channel reaches the lower threshold, a decrease in riverbank steepness can result a wider and shallower channel cross-section, while channel depth and slope remain almost unchanged.

Table 2. Equilibrium channel relations at the lower threshold under different values of bank angle $\theta$.

\begin{tabular}{|c|c|c|}
\hline$\theta$ & $\zeta_{m}$ & Values of the Coefficients in Equation (22) \\
\hline $0^{\circ}$ & 2 & $\begin{array}{l}a=3.5613 \\
b=1.7807 \\
c=2.6131 \times 10^{-5} \\
a=4.3948\end{array}$ \\
\hline $30^{\circ}$ & 2.31 & $\begin{array}{l}b=1.9025 \\
c=2.4453 \times 10^{-5} \\
a=5.2499\end{array}$ \\
\hline $45^{\circ}$ & 2.83 & $\begin{array}{l}b=1.8551 \\
c=2.5071 \times 10^{-5} \\
a=6.7210\end{array}$ \\
\hline $60^{\circ}$ & 4 & $\begin{array}{l}b=1.6803 \\
c=2.7693 \times 10^{-5}\end{array}$ \\
\hline
\end{tabular}

\subsection{Averaged Equilibrium Channel Relations}

When flow in a river channel is in the state of $\tau_{0}>\tau_{c}$, it can be seen from Equations (18) and (19) that there is no upper limit for Equation (15) to be satisfied or for sediment (bedload) discharge $Q_{s}$ to reach $Q_{\text {smax }}$. Hence, when $Q_{s}=Q_{\text {smax }}$, combining Equations (18) and (17) with Equations (7) to (9) and the relationship of $Q_{s}=q_{b} P_{b}=q_{b}(W-2 D \tan \theta)$, and then eliminating channel slope $S$ such that the optimal channel width-depth ratio $\zeta_{m}$ can be expressed as a function of flow discharge $Q$, sediment discharge $Q_{s}$, sediment size $d$, roughness coefficient $n$ and the angle of channel banks $\theta$ in the form of:

$$
\begin{aligned}
& \left(\frac{-(5 / 3) B^{1}}{F^{1}-C^{1}+(5 / 3) B^{1}}\right)^{65 / 9} \frac{F^{1}-C^{1}+(5 / 3) B^{1}}{F^{1}-C^{1}} \frac{\left(\zeta_{m}-2 \tan \theta\right)^{13 / 3}}{\left(\zeta_{m}-\tan \theta\right)^{7 / 3}}\left(\zeta_{m}+2 \sec \theta-2 \tan \theta\right)^{1 / 3} \\
& =3.0725 * 10^{2} d^{-11 / 2} \frac{Q_{s}^{13 / 3}}{(n Q)^{2}}
\end{aligned}
$$

Consequently, the following relationships can be derived by combining Equation (23) with Equations (18), (17), (6) and (9) to determine equilibrium channel slope $S_{m}$, width $W_{m}$ and depth $D_{m}$ as:

$$
\begin{gathered}
S_{m}=\left(\frac{-(5 / 3) B^{1}}{A^{1}-C^{1}+(5 / 3) B^{1}}\right)^{80 / 9} \frac{\left(\zeta_{m}-2 \tan \theta\right)^{16 / 3}}{\left(\zeta_{m}-\tan \theta\right)^{10 / 3}}\left(\zeta_{m}+2 \sec \theta-2 \tan \theta\right)^{4 / 3} * \\
\left(3.7136 * 10^{-5} d^{8} \frac{(n Q)^{2}}{Q_{s}^{16 / 3}}\right) \\
W_{m}=\frac{Q_{s} \zeta}{1.4768 * 10^{-1} d^{3 / 2}\left(\frac{-(5 / 3) B^{1}}{A^{1}-C^{1}+(5 / 3) B^{1}}\right)^{5 / 3}(\zeta-2 \tan \theta)} \\
D_{m}=\frac{Q_{s} \zeta}{1.4768 * 10^{-1} d^{3 / 2} \zeta\left(\frac{-(5 / 3) B^{1}}{A^{1}-C^{1}+(5 / 3) B^{1}}\right)^{5 / 3}(\zeta-2 \tan \theta)}
\end{gathered}
$$

Equations (18) and (19) show clearly that theoretically there is no upper limit in the variation of $\zeta_{m}$, that is $\zeta_{m}$ can take any value in the range of $\zeta_{m c}$ to $+\infty$ under the given conditions. However, 
the width-depth ratios of actual river channels rarely exceed 1000, and so we assume that the maximum value of $\zeta_{m}$ is 1000. Nevertheless, Equation (18) shows that bank angle $\theta$ has a significant influence on $\zeta_{m}$ and when $\theta$ takes a value of $60^{\circ}$, letting $\zeta_{m}$ vary from $\zeta_{m c}$ to 1000 requires $\tau_{0} / \tau_{c}$ to change in the range of from 1 to 195.70 . By assuming that when $\theta$ takes values other than $60^{\circ}$ and letting $\tau_{0} / \tau_{c}$ vary in the range of from 1 to 195.70 in all cases, the potential varying range of $\zeta_{m}$ for each given value of $\theta$ can be calculated from Equation (18). Table 3 presents the calculated results, with the potential varying ranges of $\zeta_{m}$ being defined in integers approximately.

Table 3. Values and potential varying ranges of optimal channel width/depth ratio $\zeta_{m}$ under different values of bank angle $\theta$.

\begin{tabular}{ccc}
\hline $\boldsymbol{\theta}$ & $\zeta_{\boldsymbol{m}}$ & $\begin{array}{c}\text { Potential Varying } \\
\text { Range of } \zeta_{\boldsymbol{m}}\end{array}$ \\
\hline $0^{\circ}$ & 625 & $3-625$ \\
$30^{\circ}$ & 749.8 & $3-749$ \\
$45^{\circ}$ & 878.2 & $3-878$ \\
$60^{\circ}$ & 1000 & $5-1000$ \\
\hline
\end{tabular}

Since the equilibrium channel relations presented in Equations (23)-(26) are in very complex forms, typically the terms containing $\zeta_{m}$. By allowing $\theta$ to take a value of $0^{\circ}$ and $\zeta_{m}$ vary from 3 to 625 with an increment of 1 in terms of the results presented in Table 4, regression analyses are conducted and the complex terms containing $\zeta_{m}$ in Equations (23)-(26) can be expressed approximately in the averaged forms respectively as:

$$
\begin{gathered}
\left(\frac{-(5 / 3) B^{1}}{A^{1}-C^{1}+(5 / 3) B^{1}}\right)^{65 / 9} \frac{A^{1}-C^{1}+(5 / 3) B^{1}}{A^{1}-C^{1}} \zeta_{m}^{2}\left(\zeta_{m}+2\right)^{1 / 3} \approx 1 * 10^{-4} \zeta_{m}^{8.8809}, R^{2}=0.998 \\
\left(\frac{-(5 / 3) B^{1}}{A^{1}-C^{1}+(5 / 3) B^{1}}\right)^{80 / 9} \zeta_{m}^{2}\left(\zeta_{m}+2\right)^{4 / 3} \approx 4 * 10^{-6} \zeta_{m}{ }^{12.5699}, \quad R^{2}=0.9988 \\
\left(\frac{-(5 / 3) B^{1}}{A^{1}-C^{1}+(5 / 3) B^{1}}\right)^{5 / 3} \approx 0.0935 * \zeta_{m}^{1.7396}, \quad R^{2}=0.9934 \\
\left(\frac{-(5 / 3) B^{1}}{A^{1}-C^{1}+(5 / 3) B^{1}}\right)^{5 / 3} \zeta_{m} \approx 0.0935 * \zeta_{m}^{2.7396}, \quad R^{2}=0.9974
\end{gathered}
$$

Incorporating relations in Equations (27)-(30) into Equations (23)-(26), the following averaged equilibrium channel relations can be obtained:

$$
\begin{aligned}
& W_{m}=7.4642 * 10^{5} d^{1.0773}(n Q)^{0.3918} Q_{s}^{0.1512}=7.4642 * 10^{5} d^{1.0773} n^{0.3918}\left(\frac{Q_{s}}{Q}\right)^{0.1512} Q^{0.5430} \\
& D_{m}=1.3887 * 10^{5} d^{1.6967}(n Q)^{0.6170} Q_{s}^{-0.3386}=1.3887 * 10^{5} d^{1.6967} n^{0.6170}\left(\frac{Q_{s}}{Q}\right)^{-0.3368} Q^{0.2802} \\
& S_{m}=0.2268 d^{0.2159}(n Q)^{-0.8306} Q_{s}^{0.7996}=0.2268^{d 0.2159} n^{-0.8306}\left(\frac{Q_{s}}{Q}\right)^{0.7996} Q^{-0.0310}
\end{aligned}
$$

In a similar way, the averaged equilibrium channel relations for bank angle $\theta$ to take respective values of $30^{\circ}, 45^{\circ}$ and $60^{\circ}$ can be obtained. Table 4 presents the equilibrium channel relations for all of the four cases when bank angle $\theta$ takes respective values of $0^{\circ}, 30^{\circ}, 45^{\circ}$ and $60^{\circ}$, and it can be seen clearly that the four independent variables of sediment size $d$, channel roughness coefficient $n$, flow discharge $Q$ and sediment discharge $Q_{s}$ all play very important roles in shaping river channel forms. To examine if bank angle $\theta$ affects the performance of the four variables, the varying ranges of 
the exponents of the four variables in four sets of equilibrium channel relations for bank angle $\theta$ to take significantly different values of $0^{\circ}, 30^{\circ}, 45^{\circ}$ and $60^{\circ}$ are summarized from Table 4 as:

$$
\begin{aligned}
& W_{m}=K_{W} d^{1.0773 \sim 1.0918} n^{0.3918 \sim 0.3966}\left(\frac{Q_{s}}{Q}\right)^{0.1407 \sim 0.1512} Q^{0.5373 \sim 0.5430} \\
& D_{m}=K_{D} d^{1.6838 \sim 1.6967} n^{0.6124 \sim 0.6170}\left(\frac{Q_{s}}{Q}\right)^{-(0.3368 \sim 0.3269)} Q^{0.2802 \sim 0.2855} \\
& S_{m}=K_{s} d^{0.2159 \sim 0.2469} n^{-(0.8194 \sim 0.8306)}\left(\frac{Q_{s}}{Q}\right)^{0.7996 \sim 0.7754} Q^{-(0.0310 \sim 0.044)}
\end{aligned}
$$

where $K_{W}, K_{D}$ and $K_{S}$ are coefficients.

It is seen clearly from Equation (32) that although bank angle $\theta$ takes significantly different values of $0^{\circ}, 30^{\circ}, 45^{\circ}$ and $60^{\circ}$, the exponents of sediment size $d$, channel roughness coefficient $n$, flow discharge $Q$ and sediment discharge $Q_{s}$ in channel width, depth and slope relations all vary in very narrow ranges. Hence, these exponents encounter almost no influences from bank angle or bank steepness and so can be regarded as constants.

The variations of coefficients $K_{W}, K_{D}$ and $K_{S}$ in Equation (32) when bank angle $\theta$ takes respective values of $0^{\circ}, 30^{\circ}, 45^{\circ}$ and $60^{\circ}$ are presented in Figure 3 . It is seen clearly that $K_{W}$ varies in a gradually increasing form, taking values of $7.4642 \times 10^{5}, 8.1238 \times 10^{5}, 9.6346 \times 10^{5}$ and $11.387 \times 10^{5}$, respectively, with an increase of up to $52.6 \%$. Nevertheless, $K_{D}$ varies in a gradually decreasing form, taking values of $1.3887 \times 10^{5}, 1.2739 \times 10^{5}, 1.1677 \times 10^{5}$ and $1.0892 \times 10^{5}$, respectively, with a $21.6 \%$ decrease in down. However, $K_{S}$ varies not in a consistent form, increasing at the early stages and finally decreasing by taking respective values of 0.2268 to $0.2744,0.3103$ and 0.2471 . The difference between the maximum and minimum values of $K_{S}$ is very small, with a value of 0.0835 , and as such, $K_{S}$ can be regarded as a constant of about 0.27 . These results demonstrate clearly that an increase in riverbank angle, that is a decrease in riverbank steepness, can result in a wider and shallower channel cross-section and vice versa. Nevertheless, such a change in bank angle $\theta$ exerts only insignificant influences on channel

\begin{tabular}{|c|c|c|}
\hline$\theta$ & $\zeta_{m}$ & Averaged Equilibrium Channel Relations \\
\hline $0^{\circ}$ & $3 \leq \zeta_{m} \leq 625$ & $\begin{array}{l}W_{m}=7.4642 * 10^{5} d^{1.0773}(n Q)^{0.3918} Q_{s}^{0.1512}=7.4642 * 10^{5} d^{1.0773} n^{0.3918}\left(\frac{Q_{s}}{Q}\right)^{0.1512} Q^{0.5430} \\
D_{m}=1.3887 * 10^{5} d^{1.6967}(n Q)^{0.6170} Q_{s}^{-0.3386}=1.3887 * 10^{5} d^{1.6967} n^{0.6170}\left(\frac{Q_{s}}{Q}\right)^{-0.3368} Q^{0.2802} \\
S_{m}=0.2268 d^{0.2159}(n Q)^{-0.8306} Q_{s}^{0.7996}=0.2268 d^{0.2159} n^{-0.8306}\left(\frac{Q_{s}}{Q}\right)^{0.7996} Q^{-0.0310}\end{array}$ \\
\hline $30^{\circ}$ & $3 \leq \zeta_{m} \leq 749$ & $\begin{array}{l}W_{m}=8.1239 * 10^{5} d^{1.0804}(n Q)^{0.3928} Q_{s}^{0.1489}=8.1239 * 10^{5} d^{1.0804} n^{0.3928}\left(\frac{Q_{s}}{Q}\right)^{0.1489} Q^{0.5417} \\
D_{m}=1.2739 * 10^{5} d^{1.6961}(n Q)^{0.6168} Q_{s}^{-0.3363}=1.2739 * 10^{5} d^{1.6961} n^{0.6168}\left(\frac{Q_{s}}{Q}\right)^{-0.3363} Q^{0.2805} \\
S_{m}=0.2744 d^{0.2210}(n Q)^{-0.8288} Q_{s}^{0.7957}=0.2744 d^{0.2210} n^{-0.8288}\left(\frac{Q_{s}}{Q}\right)^{0.7957} Q^{-0.0331}\end{array}$ \\
\hline $45^{\circ}$ & $3 \leq \zeta_{m} \leq 878$ & $\begin{array}{l}W_{m}=9.6346 * 10^{5} d^{1.0905}(n Q)^{0.3966} Q_{s}^{0.1407}=9.6346 * 10^{5} d^{1.0905} n^{0.3966}\left(\frac{Q_{s}}{Q}\right)^{0.1407} Q^{0.5373} \\
D_{m}=1.1677 * 10^{5} d^{1.6838}(n Q)^{0.6124} Q_{s}^{-0.3269}=1.1677 * 10^{5} d^{1.6838} n^{0.6124}\left(\frac{Q_{s}}{Q}\right)^{-0.3269} Q^{0.2855} \\
S_{m}=0.3103 d^{0.2469}(n Q)^{-0.8194} Q_{s}^{0.7754}=0.3103 d^{0.2469} n^{-0.8194}\left(\frac{Q_{s}}{Q}\right)^{0.7754} Q^{-0.044}\end{array}$ \\
\hline $60^{\circ}$ & $5 \leq \zeta_{m} \leq 1000$ & $\begin{array}{l}W_{m}=11.387 * 10^{5} d^{1.0918}(n Q)^{0.3960} Q_{s}^{0.1420}=11.387 * 10^{5} d^{1.0918} n^{0.3960}\left(\frac{Q_{s}}{Q}\right)^{0.1420} Q^{0.5380} \\
D_{m}=1.0892 * 10^{5} d^{1.6848}(n Q)^{0.6140} Q_{s}^{-0.3286}=1.0892 * 10^{5} d^{1.6848} n^{0.6140}\left(\frac{Q_{s}}{Q}\right)^{-0.3286} Q^{0.2854} \\
S_{m}=0.2471 d^{0.2446}(n Q)^{-0.8254} Q_{s}^{0.7884}=0.2471 d^{0.2446} n^{-0.8254}\left(\frac{Q_{s}}{Q}\right)^{0.7884} Q^{-0.037}\end{array}$ \\
\hline
\end{tabular}
slope measured by the variation of coefficient $K_{S}$.

Table 4. The averaged equilibrium channel relations under different values of bank angle $\theta$. 

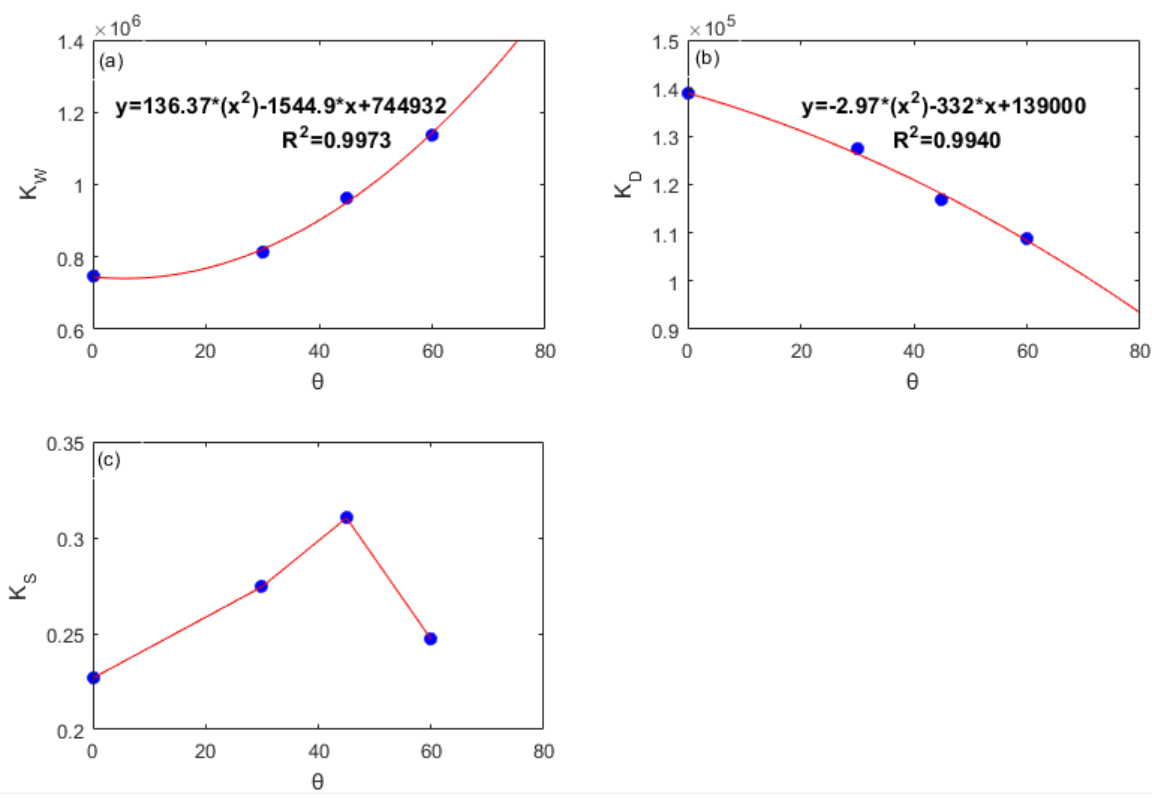

Figure 3. Relationships between coefficients $K_{W}, K_{D}$ and $K_{S}$ in equilibrium channel relations in Equation (32) and riverbank angle $\theta$ : (a) Relationship between coefficients $K_{W}$ and $\theta$; (b) Relationship between coefficients $K_{D}$ and $\theta$; and (c) Relationship between coefficients $K_{S}$ and $\theta$.

When $S$ is regarded as an independent variable and $Q_{s}$ a dependent variable, $Q_{s}$ is replaced in terms of the relationship for determining $S_{m}$ in Equation (31). As a result, the averaged equilibrium channel relations derived from Equations (31) and (1) are consistent with so-called hydraulic geometry relations as:

$$
\begin{aligned}
& W_{m}=152.4097 d^{-0.0408}(n Q)^{0.5489} S^{0.1891} \\
& D_{m}=0.0805 d^{0.0909}(n Q)^{0.2671} S^{-0.4212} \\
& V_{m}=0.0815 d^{-0.0501} n^{-0.8160} Q^{0.1840} S^{0.2321}
\end{aligned}
$$

In a similar way, the averaged hydraulic geometry relationships for $\theta$ to take respective values of $30^{\circ}, 45^{\circ}$ and $60^{\circ}$ can be obtained. Table 5 presents the equilibrium channel relations for all of the four cases when bank angle $\theta$ takes respective values of $0^{\circ}, 30^{\circ}, 45^{\circ}$ and $60^{\circ}$ and it is seen clearly that the four independent variables of sediment size $d$, channel roughness coefficient $n$, flow discharge $Q$ and sediment discharge $Q_{s}$ all play very important roles in shaping river channel forms. To examine if bank angle $\theta$ affects the performance of the four variables, the varying ranges of the exponents of the four variables in four sets of equilibrium channel relations for bank angle $\theta$ to take significantly different values of $0^{\circ}, 30^{\circ}, 45^{\circ}$ and $60^{\circ}$ are summarized from Table 5 as:

$$
\begin{aligned}
& W_{m}=K^{\prime}{ }_{W} d^{-(0.0408 \sim 0.0448)} S^{0.1768 \sim 0.1891}(n Q)^{0.5431 \sim 0.5489} \\
& D_{m}=K^{\prime}{ }_{D} d^{0.0909 \sim 1.1019} S^{-(0.4168 \sim 0.4226)}(n Q)^{0.2655 \sim 0.2692} \\
& V_{m}=K^{\prime}{ }_{V} d^{-(0.0501 \sim 0.0593)} n^{-(0.8122-0.8160)} S^{0.2321-0.4226} Q^{0.1840 \sim 0.1878}
\end{aligned}
$$

where $K^{\prime}{ }_{W}, K^{\prime}{ }_{D}$ and $K^{\prime}{ }_{V}$ are coefficients.

Equation (34) shows clearly that although bank angle $\theta$ takes significantly different values of $0^{\circ}$, $30^{\circ}, 45^{\circ}$ and $60^{\circ}$, the exponents of sediment size $d$, channel roughness coefficient $n$, flow discharge $Q$ and sediment discharge $Q_{s}$ in hydraulic geometry relations vary all in very narrow ranges. Hence, bank angle or bank steepness exerts almost no influences on these exponents and so they can be regarded as constants. 
Table 5. The averaged hydraulic geometry relations under different values of bank angle $\theta$.

\begin{tabular}{ccl}
\hline $\boldsymbol{\theta}$ & \multicolumn{1}{c}{$\zeta_{m}$} & \multicolumn{1}{c}{ Averaged Hydraulic Geometry Relations } \\
\hline & & $W_{m}=152.4097 d^{-0.0408}(n Q)^{0.5489} S^{0.1891}$ \\
$0^{\circ}$ & $3 \leq \zeta_{m} \leq 625$ & $D_{m}=0.0805 d^{0.0909}(n Q)^{0.2671} S^{-0.4212}$ \\
& & $V_{m}=0.0815 d^{-0.0501} n^{-0.8160} Q^{0.1840} S^{0.2321}$ \\
& $W_{m}=162.449 d^{-0.0414}(n Q)^{0.5479} S^{0.1871}$ \\
$30^{\circ}$ & $3 \leq \zeta_{m} \leq 749$ & $D_{m}=0.0776 d^{0.0934}(n Q)^{0.2655} S^{-0.4226}$ \\
& & $V_{m}=0.0798 d^{-0.0520} n^{-0.8134} Q^{0.1866} S^{0.2395}$ \\
& & $W_{m}=171.5476 d^{-0.0448}(n Q)^{0.5453} S^{0.1815}$ \\
$45^{\circ}$ & $3 \leq \zeta_{m} \leq 878$ & $D_{m}=0.0736 d^{0.1041}(n Q)^{0.2669} S^{-0.4216}$ \\
& & $V_{m}=0.0792 d^{-0.0593} n^{-0.8122} Q^{0.1878} S^{0.2401}$ \\
& & $W_{m}=205.509 d^{-0.0441}(n Q)^{0.5431} S^{0.1768}$ \\
$60^{\circ}$ & $5 \leq \zeta_{m} \leq 1000$ & $D_{m}=0.0698 d^{0.1019}(n Q)^{0.2692} S^{-0.4168}$ \\
& & $V_{m}=0.0697 d^{-0.0578} n^{-0.8123} Q^{0.1877} S^{0.2400}$ \\
\hline
\end{tabular}

The variations of coefficients $K^{\prime}{ }_{W}, K^{\prime}{ }_{D}$ and $K^{\prime}{ }_{V}$ in Equation (34) are presented in Figure 4 for bank angle $\theta$ to take respective values of $0^{\circ}, 30^{\circ}, 45^{\circ}$ and $60^{\circ}$. It is seen clearly from Figure 4 that $K^{\prime}{ }_{W}$ varies in a gradually increasing form, taking respective values of 152.4097, 162.499, 171.5476. and 205.509, with an increase of up to $34.84 \%$. Nevertheless, $K^{\prime}{ }_{D}$ varies in a gradually declining form, taking respective values of $0.0805,0.0776,0.0736$ and 0.0698 , with a maximum decrease of down to $86.71 \%$. Although varying in a very small range, $K^{\prime}{ }_{V}$ takes a slowly and then faster declining form, taking respective values of $0.0815,0.0798,0.0792$ and 0.0697 , with a maximum decrease of $85.52 \%$ in down. These results demonstrate clearly that an increase in bank angle or a decrease in riverbank steepness can result in a wider and shallower channel cross-section with a lower velocity and vice versa.
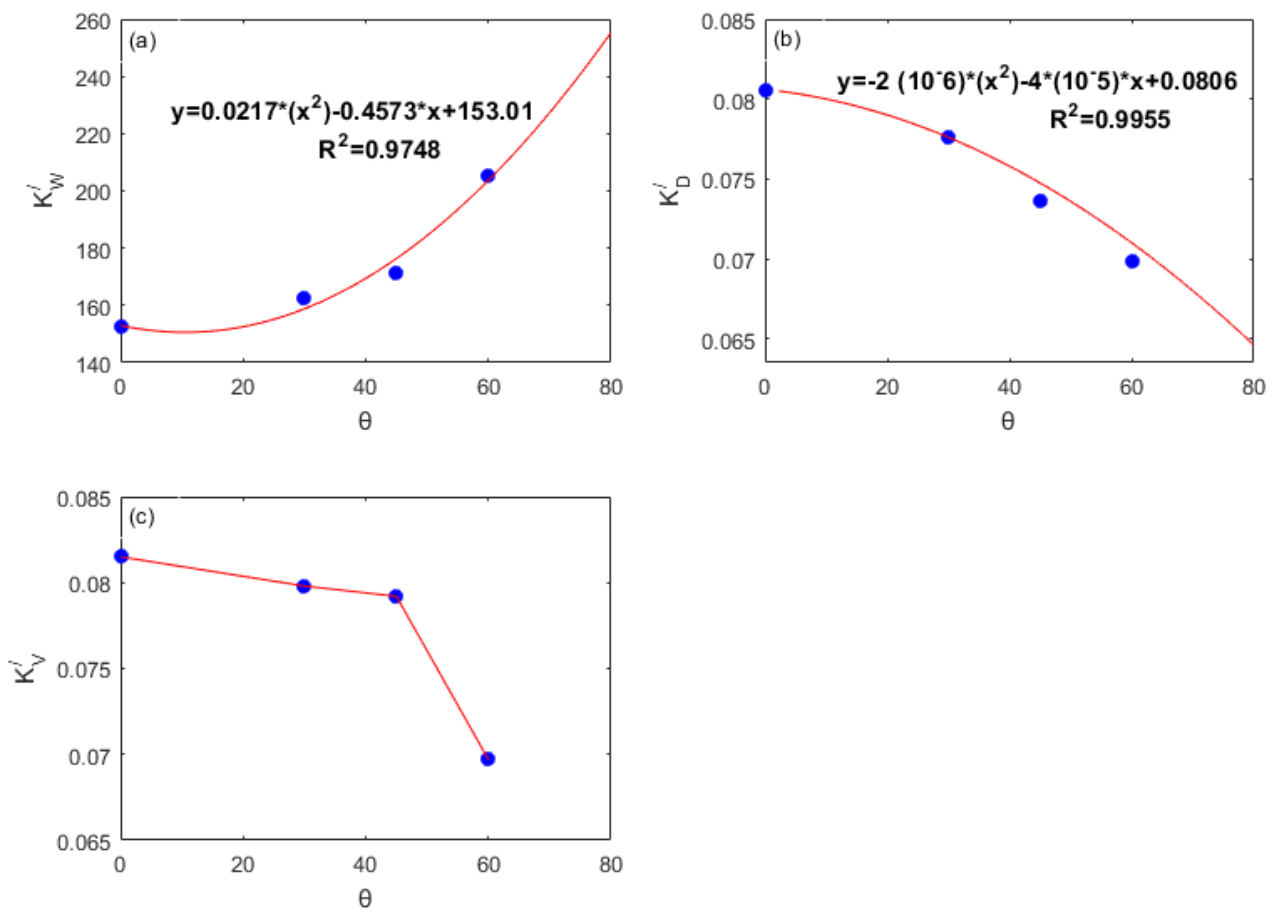

Figure 4. Relationships between coefficients $K^{\prime}{ }_{W}, K^{\prime}{ }_{D}$ and $K^{\prime}{ }_{V}$ in the averaged hydraulic geometry relations in Equation (34) and riverbank angle $\theta$ : (a) Relationship between coefficients $K^{\prime}{ }_{W}$ and $\theta$; (b) Relationship between coefficients $K^{\prime}{ }_{D}$ and $\theta$; and (c) Relationship between coefficients $K^{\prime}{ }_{V}$ and $\theta$. 


\section{Comparison of Theoretical Results with Previous Studies}

\subsection{Equilibrium Channel Relations at the Lower Threshold}

When the equilibrium channel relations at the lower threshold presented in Equation (21) are compared with those from classic "threshold theory" (e.g., Lane, 1952) [66], a perfect agreement is achieved in the reflection of the roles of flow discharge in determining river channel width, depth and slope, as shown in Table 6. However, there is a considerable difference between width/depth ratios. This is because the classic "threshold theory" assumed that sediment at every point on the wetted perimeter of the cross-section is in a state of impending motion. This embodies a very idealistic case because the banks and bed of natural river channels commonly differ significantly in the states of motion such that the width-depth ratios of the channels can take values of as low as 2 (e.g., Nanson et al., 2010) [67]. Because our study is concerned with river channels that possess different states of motion on channel banks and bed, the theoretical results of width-depth ratios obtained in our study are much closer to those of natural river channels as observed by Nanson et al. (2010) [67].

Table 6. The lower threshold channel relations in comparison with "threshold theory".

\begin{tabular}{ccc}
\hline Channel Geometry Factors & This Study & Threshold Theory (Lane, 1952) [66] \\
\hline Width $(W)$ & $W \propto Q^{0.46}$ & $W \propto Q^{0.46}$ \\
Depth $(D)$ & $D \propto Q^{0.46}$ & $D \propto Q^{0.46}$ \\
Slope $(S)$ & $S \propto Q^{-0.46}$ & $S \propto Q^{-0.46}$ \\
Width/depth ratio $(W)$ & $2-4$ & $7.05-8.61^{*}$ \\
\hline
\end{tabular}

* The angle of repose takes values of $30-35^{\circ}$.

\subsection{Averaged Equilibrium Channel Relations}

It has long been identified that flow discharge $Q$ is the predominated factor determining alluvial channel forms, with "regime theory" developed empirically from field measurements in stable canals in India, Pakistan, and the USA in early 20th century gaining worldwide recognition [10,67]. However, studies on natural river channel forms have shown that the roles of flow discharge in the one-variant hydraulic geometry model of $W \propto Q^{b}, D \propto Q^{f}$ and $V \propto Q^{m}$ vary considerably not only from one river to another, but even from one reach to another on the same river, with exponents $b, f$ and $m$ taking values ranging respectively within 0.3-0.6, 0.2-0.5 and 0.0 0.2 most frequently (Rhodes, 1987) [68]. As a result, the development of multivariant models has been practiced in recent decades. In particular, through examining the applicability of a relationship developed based on flume experimental observations between shear stress distribution on channel banks and bed with channel width/depth ratio in a wide range of stable canals and natural river channels, Huang and Warner (1995) established the following multivariant hydraulic geometry model [69]:

$$
\begin{aligned}
& W=C_{W} Q^{0.5} n^{0.355} S^{-0.156} \\
& D=C_{D} Q^{0.3} n^{0.383} S^{-0.206} \\
& V=C_{V} Q^{0.2} n^{0.383} S^{-0.206}
\end{aligned}
$$

where coefficients $C_{W}, C_{D}$ and $C_{V}$ are determined by bank strength. Using the hydraulic geometry model presented in Equation (35), Huang and Nanson (1998) performed a detailed analysis of worldwide observations on river channel forms and bank compositions, and identified that bank strength in relation to bank compositions can produce a three-fold change in channel width and about a two-fold change in depth, or $2 \leq C_{W} \leq 6.5$ and $0.33 \leq C_{D} \leq 0.63$, respectively [13]. 
Equation (35) shows clearly that besides flow discharge $Q$ channel slope $S$, channel roughness coefficient $n$ and bank strength also play very important roles in shaping river channel forms. Nevertheless, the hydraulic geometry relations theoretically derived in this study as presented in Table 5 shows that sediment size $d$ is also a very important factor that needs to be taken into account in determining river channel forms. In fact, the influence of sediment size on channel forms has long been recognized [68]. Hence, our theoretical results provide a more comprehensive hydraulic geometry model. Importantly, when the effects of the other factors including channel slope $S$, sediment size $d$, channel roughness coefficient $n$ and bank scourability are not very significant and can be ignored without causing significant errors as they are in the simple case of stable canals, Table 7 presents the comparison of the one-variant hydraulic geometry relations theoretically derived in this study with those summarized by Rhodes (1987) and developed by Huang and Warner (1995) [68,69]. It can be noticed that the exponents of flow discharge $Q$ obtained in our theoretical study fall into the most frequently occurred ranges given by Rhodes (1987), and are almost identical with the results obtained in the semi-theoretical study of Huang and Warner (1995) [69].

Table 7. Comparison of the hydraulic geometry relations obtained in this study with the studies by Rhodes (1987) [68] and by Huang and Warner (1995) [69].

\begin{tabular}{cccc}
\hline $\begin{array}{c}\text { Hydraulic Geometry } \\
\text { Factors }\end{array}$ & This Study & $\begin{array}{c}\text { Hydraulic Geometry Model } \\
\text { (Rhodes, 1987) [68] }\end{array}$ & $\begin{array}{c}\text { Huang and Warner } \\
\text { (1995) [69] }\end{array}$ \\
\hline Width $(W)$ & $W \propto Q^{0.5431 ~ 0.5489}$ & $W \propto Q^{0.3 \sim 0.6}$ & $W \propto Q^{0.5}$ \\
Depth $(D)$ & $D \propto Q^{0.2655 \sim 0.2692}$ & $D \propto Q^{0.2 ~ 0.5}$ & $D \propto Q^{0.3}$ \\
Velocity $(W)$ & $V \propto Q^{0.1840 \sim 0.1876}$ & $V \propto Q^{0.0 ~ 0.3}$ & $V \propto Q^{0.2}$ \\
\hline
\end{tabular}

Although it is generally known that bank strength or scourability can exert significant influences on river channel forms, there have been no appropriate methods to directly quantify bank strength. As a result, many qualitative indices are adopted, such as noncohesive sand, gravels, cohesive sand, tree size and more. In very detailed forms, Huang and Nanson (1998) adopted these indices in their quantification of the influences of riverbank strength on channel forms and found that bank strength can produce a three-fold change in channel width and about a two-fold change in depth [13]. For convenience to conduct mathematical analysis, this study uses bank angle to reflect bank strength and our theoretical results show clearly in Figures 3 and 4 that with a change in bank angle from $0^{\circ}$ to $60^{\circ}$, channel width can increase by $34.84 \%$, while channel depth declines by $13.29 \%$. While the trends of the influences of bank strength on channel width and depth illustrated in our theoretical results are consistent with the semi-theoretical study of Huang and Nanson (1998), large differences occur in the ranges of the influences. This is because bank angle deployed in our study can reflect bank strength of natural river channels only in the simple cases where alluvial channel banks are composed of noncohesive sand to cohesive sand. Indeed, Huang and Nanson (1998) also identified that the effects of bank strength are in the small ranges of increasing $62.2 \%$ on channel width and decreasing $26.7 \%$ on channel depth [13].

Table 8 presents a comparison of the theoretical results obtained in this study with the semi-empirical results by Huang and Nanson (1998) for the situations in which alluvial channel banks are composed of noncohesive sand to cohesive sand [13]. While it is seen clearly from Table 8 that the theoretical analysis of this study produces results highly consistent with field observations, it also highlights the need for a more detailed study on how to accurately embody the complexity and influences of bank strength on river channel forms. 
Table 8. Comparison of riverbank steepness effects on river channel forms between the theoretical results of this study and the semi-empirical results by Huang and Nanson (1998) [13].

\begin{tabular}{cccccc}
\hline \multicolumn{2}{c}{ Theoretical Results of this Study } & \multicolumn{2}{c}{ Results of Huang and Nanson (1998) [13] } \\
\hline $\begin{array}{c}\text { Bank angle } \\
\theta\end{array}$ & $\begin{array}{c}\text { Channel width } \\
\text { change (\%) }\end{array}$ & $\begin{array}{c}\text { Channel depth } \\
\text { change (\%) }\end{array}$ & Bank type & $\begin{array}{c}\text { Channel width } \\
\text { change (\%) }\end{array}$ & $\begin{array}{c}\text { Channel depth } \\
\text { change (\%) }\end{array}$ \\
\hline $0^{\circ}$ & 0 & 0 & $\begin{array}{c}\text { Cohesive sand } \\
\text { or gravels }\end{array}$ & 0 & 0 \\
$30^{\circ}$ & 8.8 & -8.3 & & & \\
$45^{\circ}$ & 29.1 & -15.9 & Noncohesive \\
sand & 62.2 & -26.7 \\
$60^{\circ}$ & 52.6 & -21.6 & & & \\
\hline
\end{tabular}

\section{Conclusions}

Although it is well known that bank anti-scourability or bank strength exerts significant impacts on river channel forms, there has been lacking a suitable method to determine the impacts. In light of the recent advancement on understanding the self-adjusting mechanism governing river channel-form adjustment, this study applies the variational analytical approach developed by Huang and Nanson [53] to investigate the influence of bank anti-scourability on alluvial channel forms. Riverbanks are normally composed of various materials and take considerably different profiles, and as such, this study uses an isosceles trapezoid as the generalized cross-sectional form of river channels. Taking the angle of channel banks $\theta$ as the main factor to reflect the anti-scourability of riverbanks, our detailed mathematical analysis of the variation of sediment (bedload) discharge with changes in the variational variable of channel width/depth ratio and bank angle $\theta$ yields the following results:

(1). For a given bank angle $\theta$, flow achieves stable equilibrium in alluvial channels when sediment discharge reaches a maximum at a width-depth ratio which is not very large nor very small. With a change in bank angle $\theta$ from $0^{\circ}$ to $60^{\circ}$ to reflect a decrease in the steepness of channel banks, maximum sediment discharge declines slightly while optimal width/depth ratio increases very significantly. This is because the change in bank angle, while the channel bed remains unchanged, can result in a significant change in channel width and width-depth ratio, while the hydraulic radius changes only slightly.

(2) When flow in alluvial channels is at the critical state for the incipient motion of bed sediment, the roles of flow discharge in our theoretically derived equilibrium channel relations are in a perfect agreement with those from classic "threshold theory", and the width-depth ratios obtained in our study are much closer to those of natural river channels.

(3) When flow in alluvial channels has excessive shear to transport sediment (bedload), our theoretical analysis shows that equilibrium channel relations are determined by multiple variables, including flow discharge, bed sediment size, channel roughness coefficient, sediment (bedload) concentration or channel slope and bank angle. Importantly, this study finds that only when the effects of the other variables on channel forms are so small as to be ignored, such as in irrigation canals, are the roles of flow discharge in shaping channel forms highly consistent with the results of empirically based studies. Hence, the hydraulic geometry model developed in this study not only has a sounder physical base, but also takes a more comprehensive form than the other models developed previously.

(4) When bank angle changes from $0^{\circ}$ to $60^{\circ}$, no significant responses can be found in the roles of flow discharge, sediment size, channel roughness coefficient and sediment discharge or channel slope in the averaged hydraulic geometry relations, and yet an increase of $34.84 \%$ in channel width and a decrease of $13.29 \%$ in channel depth take place.

Rivers have a self-adjusting character in shaping channel forms and the variational analytical approach developed by Huang and Nanson has been proven physically sound and robust in uncovering the character in many circumstances $[5,6,52,53,62]$. Using this approach, this study successfully develops a hydraulic geometry model in which the effects of riverbank anti-scourability on channel forms gain 
reasonable quantifications. However, this study is conducted with an assumption that the cross-sections of river channels can be illustrated with an isosceles trapezoid. In reality, however, this assumption is valid only in very limited circumstances and so care needs to be taken when applying the theoretical results of this study in practical problems solving.

Author Contributions: Conceptualization, J.F. and H.H.; methodology, J.F., H.H., and G.Y.; software, J.F.; validation, J.F., H.H. and T.S.; formal analysis, J.F. and H.H.; investigation, J.F., H.H., G.Y., T.S.; resources, J.F. and G.Y.; data curation, J.F.; writing — original draft preparation, J.F.; writing—-review and editing, J.F. and H.H.; visualization, J.F., H.H. and H.Y.; supervision, H.H. and G.Y.; project administration, H.H. and G.Y.; funding acquisition, H.H. All authors have read and agreed to the published version of the manuscript.

Funding: This research was financially supported by the National Key Research and Development Program of China (2016YFC0402502) and the National Natural Science Foundation of China (Grant Nos. 41561144012, 41661144030, 41971010).

Conflicts of Interest: The authors declare no conflict of interest.

\section{References}

1. Blench, T. Mobile Bed Fluviology; University of Alberta Press: Edmonton, AB, Canada, 1969; 164p.

2. Mackin, J. Concept of the graded river. GSA Bull. 1948, 59, 463. [CrossRef]

3. Huang, H.Q.; Chang, H.H.; Nanson, G.C. Minimum energy as the general form of critical flow and maximum flow efficiency and for explaining variations in river channel pattern. Water Resour. Res. 2004, 40, 13. [CrossRef]

4. Nanson, G.C.; Huang, H.Q. Least action principle, equilibrium states, iterative adjustment and the stability of alluvial channels. Earth Surf. Process. Landf. 2008, 33, 923-942. [CrossRef]

5. Nanson, G.C.; Huang, H.Q. Self-adjustment in rivers: Evidence for least action as the primary control of alluvial-channel form and process. Earth Surf. Process. Landf. 2017, 42, 575-594. [CrossRef]

6. Nanson, G.C.; Huang, H.Q. A philosophy of rivers: Equilibrium states, channel evolution, teleomatic change and least action principle. Geomorphology 2018, 302, 3-19. [CrossRef]

7. Lane, E.W. The design of stable channels. Transactions 1955, 120, 1234-1279.

8. Lane, E.W. A Study of the Shape of Channels Formed by Natural Streams Flowing in Eroding Material, M R D Sediment Series; U.S. Army Engineer Division, Missouri River, Corps of Engineers: Omaha, NE, USA, 1957.

9. Schumm, S.A. Fluvial Geomorphology: The historical perspective. In River Mechanics; Shen, H.W., Ed.; Box 606: Fort Collins, CO, USA, 1971.

10. Andrews, E.D. Bed-material entrainment and hydraulic geometry of gravel-bed rivers in Colorado. GSA Bull. 1984, 95, 371. [CrossRef]

11. Hey, R.D.; Thorne, C.R. Stable channels with mobile gravel beds. J. Hydraul. Eng. 1986, 112, 671-689. [CrossRef]

12. Huang, H.Q.; Nanson, G.C. Vegetation and channel variation; A case study of four small streams in southeastern Australia. Geomorphology 1997, 18, 237-249. [CrossRef]

13. Huang, H.Q.; Nanson, G.C. The influence of bank strength on channel geometry: An integrated analysis of some observations. Earth Surf. Process. Landf. 1998, 23, 865-876. [CrossRef]

14. Lacey, G. Stable channels in alluvium. Min. Proc. Inst. Civ. Eng. 1930, 229, 259-292. [CrossRef]

15. Leopold, L.B.; Maddock, T. The hydraulic geometry of stream channels and some physiographic implications. Prof. Paper 1953, 252. [CrossRef]

16. Leopold, L.B.; Wolman, M.G. River Channel Patterns: Braided, Meandering and Straight, US Geological Survey Professional Paper; US Government Printing Office: Washington, DC, USA, 1957.

17. Schumm, S.A. The Shape of Alluvial Channels in Relation to Sediment Type, Erosion and Sedimentation in a Semiarid Enviroment, US Geological Survey Professional Paper; US Government Printing Office: Washington, DC, USA, 1960; pp. 17-30.

18. Schumm, S.A. Geomorphic Thresholds and the Complex Response of Drainage System, Fluvial Geomorphology; Publications of Geomorphology, State University of New York: New York, NY, USA, 1973; pp. 299-310.

19. Schumm, S.A. The Fluvial System; A Wiley-Interscience Publication: Hoboken, NJ, USA, 1977.

20. Schumm, S.A. Experimental Fluvial Geomorphology; John Wiley \& Sons: Hoboken, NJ, USA, 1987.

21. Schumm, S.A.; Khan, H.R. Experimental study of channel patterns. GSA Bull. 1972, 83, 1755. [CrossRef]

22. Henderson, F.M. Open Channel Flow; Macmillan Pub, Co.: New York, NY, USA, 1966. 
23. Ikeda, S.; Parker, G.; Kimura, Y. Stable width and depth of straight gravel rivers with heterogeneous bed materials. Water Resour. Res. 1988, 24, 713-722. [CrossRef]

24. Parker, G. Self-Formed Straight Rivers with Equilibrium Banks and Mobile Bed. 1. Sand-Silt River. J. Fluid Mech. 1978, 89, 109-125. [CrossRef]

25. Parker, G. Self-Formed Straight Rivers with Equilibrium Banks and Mobile Bed. 2. Gravel River. J. Fluid Mech. 1978, 89, 127-146. [CrossRef]

26. Eaton, B.; Millar, R. Predicting gravel bed river response to environmental change: The strengths and limitations of a regime-based approach. Earth Surf. Process. Landf. 2016, 42, 994-1008. [CrossRef]

27. Chang, H.H. Geometry of rivers in regime. J. Hydraul. Div. ASCE 1979, 105, 691-706.

28. Chang, H.H. Minimum stream power and river channel patterns. J. Hydrol. 1979, 41, 303-327. [CrossRef]

29. Chang, H.H. Geometry of gravel streams. J. Hydraul. Div. ASCE 1980, 106, 1443-1456.

30. Chang, H.H. Stable alluvial canal design. J. Hydraul. Div. ASCE 1980, 106, 873-891.

31. Chang, H.H. Mathematical-model for erodible channels. J. Hydraul. Div. ASCE 1982, 108, 678-689.

32. Chang, H.H. Analysis of river meanders. J. Hydraul. Div. ASCE 1984, 110, 37-50. [CrossRef]

33. Chang, H.H. Modeling of river channel changes. J. Hydraul. Div. ASCE 1984, 110, 157-172. [CrossRef]

34. Chang, H.H. River morphology and thresholds. J. Hydraul. Div. ASCE 1985, 111, 503-519. [CrossRef]

35. Mengoni, B.; Paris, E.; Bettess, R. Analytical approach to river regime. J. Hydraul. Div. ASCE 1982, 108, 1179-1193.

36. Yang, C.T. Unit stream power and sediment transport. J. Hydraul. Div. ASCE 1974, 100, 1269-1272.

37. Yang, C.T. Minimum unit stream power and fluvial hydraulics. J. Hydraul. Div. ASCE 1976, 102, 919-934.

38. Yang, C.T. Minimum unit stream power and fluvial hydraulics. J. Hydraul. Div. ASCE 1978, 104, $122-125$.

39. Yang, C.T. Unit stream power equations for total load. J. Hydrol. 1979, 40, 123-138. [CrossRef]

40. Yang, C.T. Unit stream power equation for gravel. J. Hydraul. Div. ASCE 1984, 110, 1783-1797. [CrossRef]

41. Yang, C.T.; Molinas, A. Sediment transport and unit stream power function. J. Hydraul. Div. ASCE 1982, 108, 774-793.

42. Yang, C.T.; Song, C.C.S. Theory of minimum rate of energy-dissipation. J. Hydraul. Div. ASCE 1979, 105, 769-784.

43. Yang, C.T.; Song, C.C.S.; Woldenberg, M.J. Hydraulic geometry and minimum rate of energy-dissipation. Water Resour. Res. 1981, 17, 1014-1018. [CrossRef]

44. Yang, C.T.; Stall, J.B. Applicability of unit stream power equation-closure. J. Hydraul. Div. ASCE 1978, 104, 1095-1103.

45. Yang, C.T.; Stall, J.B. Applicability of unit stream power equation. J. Hydraul. Div. ASCE 1978, 104, $289-297$.

46. Ferguson, R.I. Hydraulics and hydraulic geometry. Prog. Phys. Geogr. Earth Environ. 1986, 10, 1-31. [CrossRef]

47. Griffiths, G.A. Extremal Hypotheses for River Regime: An Illusion of Progress. Water Resour. Res. 1984, 20, 113-118. [CrossRef]

48. Chang, H.H. Comment on "Extremal hypotheses for river regime: An illusion of progress" by George A. Griffiths. Water Resour. Res. 1984, 20, 1767-1768. [CrossRef]

49. Eaton, B.C.; Millar, R.G. Optimal alluvial channel width under a bank stability constraint. Geomorphology 2004, 62, 35-45. [CrossRef]

50. Song, C.C.S.; Yang, C.T. Comment on "Extremal hypotheses for river regime:An illsion of progress" by George A. Griffiths. Water Resour. Res. 1986, 22, 993-994. [CrossRef]

51. Millar, R.G. Theoretical regime equations for mobile gravel-bed rivers with stable banks. Geomorphology 2005, 64, 207-220. [CrossRef]

52. Huang, H.Q.; Chang, H.H. Scale independent linear behavior of alluvial channel flow. J. Hydraul. Div. ASCE 2006, 132, 722-730. [CrossRef]

53. Huang, H.Q.; Nanson, G.C. Hydraulic geometry and maximum flow efficiency as products of the principle of least action. Earth Surf. Process. Landf. 2000, 25, 1-16. [CrossRef]

54. Huang, Q.H.; Nanson, G.C. Alluvial channel-form adjustment and the variational principle of least action. In Proceedings of the Congress-International Association for Hydraulic Research, Beijing, China, 16-21 September 2001; pp. 402-408.

55. Huang, H.Q.; Nanson, G.C. A stability criterion inherent in laws governing alluvial channel flow. Earth Surf. Process. Landforms 2002, 27, 929-944. [CrossRef] 
56. Huang, H.Q.; Nanson, G.C. Why some alluvial rivers develop an anabranching pattern. Water Resour. Res. 2007, 43, 12. [CrossRef]

57. Millar, R.G. An Optimization Model for the Development and Response of Alluvial River Channels. Ph.D. Thesis, University of British Columbia, Vancouver, BC, Canada, 1994.

58. Millar, R.G. Influence of bank vegetation on alluvial channel patterns. Water Resour. Res. 2000, 36, 1109-1118. [CrossRef]

59. Millar, R.G.; Quick, M.C. Effect of bank stability on geometry of gravel rivers. J. Hydraul. Eng. 1993, 119, 1343-1363. [CrossRef]

60. Millar, R.G.; Quick, M.C. Stable width and depth of gravel-bed rivers with cohesive banks. J. Hydraul. Div. ASCE 1998, 124, 1005-1013. [CrossRef]

61. Chien, N. Meyer-Peter Formula for Bed Load Transport Aniond Einstein Bed Load Function; University of California: Berkeley, CA, USA, 1954.

62. Huang, H.Q. Reformulation of the bed load equation of Meyer-Peter and Muller in light of the linearity theory for alluvial channel flow. Water Resour. Res. 2010, 46, 09533. [CrossRef]

63. Meyer-Peter, E.; Muller, R. Formulas for Bed-Load Transport. InIAHSR 2nd Meeting, Stockholm, Appendix 2; IAHR: Madrid, Spain, 1948.

64. Einstein, H.A. Formula for transportation of bed load. Trans. ASEC 1942, 107, 561-597.

65. Einstein, H.A. The Bed Load Function for Sediment Transportation in Open Channel Flows; S. Department of Agriculture, Technical Bulletion: Washington, DC, USA, 1950; p. 71.

66. Lane, E.W. Progress Report on Results of Studies on Design of Stable Channels; Hydraulic laboratory Report Hyd-352; US Bureau of Reclamation: Washington, DC, USA, 1952.

67. Nanson, R.A.; Nanson, G.C.; Huang, H.Q. The hydraulic geometry of narrow and deep channels: Evidence for flow optimisation and controlled peatland growth. Geomorphology 2010, 117, 143-154. [CrossRef]

68. Rhodes, D.D. The b-f-m diagram for downstream hydraulic geometry. Geogr. Ann. Ser. A Phys. Geogr. 1987, 69, 147. [CrossRef]

69. Huang, H.Q. The multivariate controls of hydraulic geometry: A causal investigation in terms of boundary shear distribution. Earth Surf. Process. Landforms 1995, 20, 115-130. [CrossRef] 